\title{
'There's no Physical Activity in Physical Education': The Challenges of Studying Senior PDHPE in NSW, Australia
}

\author{
Kathie Ardzejewska ${ }^{1, *}$, Antonio Piscioneri ${ }^{1} \&$ Kim Goode ${ }^{1}$ \\ ${ }^{1}$ Australian College of Physical Education, Olympic Park, Australia \\ *Corresponding author: Locked Bag 2000. Concord West, 2138, Australia. Tel: 61-2-9739-3338. E-mail: \\ kardzejewska@acpe.edu.au
}

Received: June 30, 2014

Accepted: August 29, $2014 \quad$ Online Published: September 4, 2014

doi:10.5430/wje.v4n5p1

URL: http://dx.doi.org/10.5430/wje.v4n5p1

\begin{abstract}
Using the theoretical frameworks of change and student voice this study examined whether the enactment of the senior Personal Development, Health and Physical Education (PDHPE) syllabus was received positively by students in light of their previous experience with the junior PDHPE syllabus. In addition, the study sought to examine whether there were any differences between the attitudes of females and males. Thirty seven senior students and two PDHPE teachers from a coeducational Christian school located in a middle class metropolitan Sydney area were recruited for this study. A mixed method approach of questionnaire followed by interview was used. The data revealed that the main factors that influenced student attitudes were the disconnect in both the content focus and pedagogical practice between the junior and senior syllabi. Females reported a more positive experience and were more motivated than their male peers. The main concern for the students was the limited opportunities for physical activity and they reported that they liked studying 'health' topics the least. Whether the students saw the change as manageable depended largely on their view of their teacher. Given the findings, it is recommended that attempts should be made to close the gap between the junior and senior PDHPE syllabi. It would also benefit student transition to senior PDHPE study if there were greater dialogue between students and teachers to clarify their perceptions and expectations of each other.
\end{abstract}

Keywords: Physical Education; curriculum; student-centred teaching; change

\section{Introduction}

Educational change, above all, is a people-related phenomenon for each and every individual. Students, even little ones, are people, too. Unless they have some meaningful (to them) role in the enterprise, most educational change, indeed most education, will fail (Fullan, 2007, p.170).

In the Australian state of New South Wales (NSW), students are subject to stage based learning; those in years 9 and 10 are regarded as stage five (junior), and students in year 11 and 12 are referred to as stage six (senior). Students in stage six undertake non-compulsory study choosing the subjects that they may study for the Higher School Certificate (HSC) (the exception is English which is compulsory). The HSC is the qualification students earn on completing their secondary school studies. Personal Development, Health and Physical Education (PDHPE) is becoming an increasingly popular HSC elective in NSW ranking fifth behind English, Mathematics, Biology and Business Studies in 2010 (Board of Studies [BOS]). From its inclusion as an HSC subject male enrolments outweighed females. However in 1997 the trend reversed suggesting that the stage six PDHPE course had either become more appealing for female students or less appealing for males. Interestingly, a new stage 6 PDHPE curriculum was introduced in 1999. Cliff (2007) explained that the new curriculum included a more sociological perspective on health. While Cliff (2012, p. 298) argued that the PDHPE senior syllabus drew 'on knowledge ... from scientific disciplines ... to ensure it was rigorous and demanding' it might also be argued that the inclusion of a sociocultural perspective made the course more academic in rigour. Such a perspective provides students with the opportunity to draw on the discourses of postmodernism and engage in critical analysis of the lived experiences of health and physical activity. Indeed Cliff (2012) reported that the 1999 stage 6 syllabus drew heavily from Germov's explanation that health inequalities are socially constructed. 
A superficial view of the Stage 5 and 6 syllabi would perceive a presumed alignment, however a closer examination suggests a substantial change in the focus of learning between the two stages. Based on the method used by Cassidy and Ovens (2009) to compare the New Zealand Health and Physical Education curriculum documents over time, an analysis of the Stage five and six syllabi was undertaken. The comparison of syllabus descriptors showed that there is a shift from a focus on physical activity and general lower order thinking skills to the deeper analysis of the reasons for participation in various health related activities. For example, the focus of Stage 5 is identifiable through the terms "participate", "practice" and "demonstrate"; which the Department of Education and Communities (DECNSW) (2011) refer to as engagement in skill based activities. On the other hand, terms which refer to higher order thinking skills such as "analyses", "analysis", "examine" and "research" are far more abundant in Stage six. The change to Stage 6 also sees a shift in emphasis where schools become increasingly focused on academic aptitude. As a result, students experience Stage six as a 'high stakes' period of education where exam success is perceived to have a direct relationship with a better future (Rudduck, Chaplin \& Wallace, 1996 as cited by Fullan, 2007, p. 179 ).

Together these changes suggest that there is a difference between students' experiences of Stage five and Stage six PDHPE. Nevertheless, there is a dearth of research exploring whether enrolment patterns are related to this shift in pedagogical focus. There are two intertwining theoretical frameworks that may help explore this phenomenon. The first is student voice (Rudduck \& Flutter, 2000). Despite evidence of the importance of allowing students a voice (Brooker \& Macdonald, 1999; Graham, 1995a; Hunter, 2009; Rudduck \& Flutter, 2000) when it comes to curriculum change, implementation, and reform, Fullan (2007) argues that students are rarely heard from. Research in Health and Physical Education (HPE) in Australia perhaps bucks this trend revealing a genuine interest in exploring student attitudes towards the subject (Graham, 1995b) as well as a substantial body of evidence that asks students how they interpret and reconstruct the HPE curriculum (see for example Halse, Honey \& Boughtwood, 2007; Lee \& Macdonald, 2010; Light \& Kirk, 2000). Combining the schools of thought regarding change, with that of student voice can provide a powerful opportunity for students to explain their perceptions of curriculum shift.

Fullan and Stiegelbauer (1991) suggested that there are four possible attitudinal responses from students that can be reflected in their behaviour toward change. 'Indifference' involves the student not noticing the change or being unfazed while some students use change as an opportunity for 'temporary escape'. Conversely, the shift in curriculum from year 10 to 11 can 'heighten the interest' of some students, while others can be left feeling 'confused'. The most concerning of the attitudinal responses identified later by Fullan in 2007 is 'alienation' which occurs as a result of misdirected change or as a result of students experiencing rapid and substantive change. This study set out to seek the views of students about whether:

- the change in curriculum focus between years 10 and 11 in PDHPE affected their attitude; and

- there was a variation in attitudes with respect to gender.

\section{Methodology}

This study employed a sequential mixed method design. One sequential quantitative-qualitative (QUAN $\rightarrow$ QUAL) design uses nested samples for the qualitative component (Tashakkori \& Teddlie, 2003). Such a design allows for the collection and analysis of quantitative data followed by the analysis of qualitative data produced by a purposeful criterion sample (Onwuegbuzie \& Collins, 2004). Using this strategy, it is theoretically possible to locate groups of people or patterns using quantitative analysis, and explore or elaborate on these results through the collection of qualitative data. In this way the purpose of using the mixed-method design is known as an explanatory process (Creswell, Plano Clark, Gutmann \& Hanson, 2003). Phase one of this study used a questionnaire and in phase two, an interview was used.

The participants included in the study were two year 11 PDHPE classes $(\mathrm{N}=37)$ and their respective teachers from a coeducation Christian school in a middle class suburb of Sydney. Sixteen of the students were females (43\%) and 21 (57\%) were males. Each student completed a questionnaire. Subsequently, four males and three females participated in an interview. The teachers participated in separate interviews with results compared to that of the students. This study was granted ethics approval from the institution and the school and adhered to ethical practices around consent and confidentiality.

\subsection{The Questionnaire}

A questionnaire was developed from information gained from a focus group. The moderator guide focused on unpacking the general theme of attitude change as defined by Fullan and Stiegelbauer (1991) and Fullan (2007). Questions also explored perceptions of the stage five and six syllabi and the related positives and negatives of the 
student experience. It was not possible to draw a focus group from a similar group at another school due to ethical procedures, nor was it possible to use a year 12 class from the same school due to their study commitments. Instead focus group participants were recruited amongst first year Bachelor of Health and Movement students from a tertiary institution who had recently completed year 12 PDHPE as they were considered to be similar in experience. The data from the focus group was thematically analysed (Merriam, 1998) and formed the basis of the questionnaire.

A questionnaire was chosen in order to provide students with a discreet method to document their true feelings away from the presence of the researcher. The first section examined student demographics. The second explored the feelings of students towards the year 10 course while the third explored their perceptions regarding the year 11 course and whether it met their expectations. To establish a baseline students were asked to compare the change between years 10 and 11 in the subject English, to that of PDHPE. Students were also given the opportunity to consider what changes to stage 6 they would like to see incorporated in PDHPE. The final section delved into the perceptions of the change from year 10 to 11 PDHPE through the dimensions of change: heightened interest; temporary escape; indifference; confusion; and alienation. Students were asked to separately rate their perceptions of how closely a dimension represented their experience of year 10 and 11 using a Likert scale from 1 to 5 (whereby 1 was very different and 5 was very close to their experience). A number of open ended questions were also used to allow the students to use their own language and terminology in an attempt to explain and qualify their responses (Andrews, Mason \& Silk, 2006).

The data surrounding the attitude dimension from the questionnaire was first analysed using descriptive statistics. This was followed by non-parametric analysis. In this study non-parametric tests were not used to generalise about populations but rather implemented for comparative purposes within the context of this study. A Wilcoxon (matched pairs) signed rank test was used to analyse the statistical significance of data when keeping gender constant. In order to be statistically significant, P must have been a value of less than 0.05 .

\subsection{Interviews}

Students were purposefully selected for an interview based on the ideas they had raised in the questionnaire $(\mathrm{n}=7)$. A semi structured interview was used to delve deeper into their questionnaire responses (Kvale \& Brinkmann, 2009). The two teachers who taught year 11 were also selected for interviews. Both groups were asked to reflect on the PDHPE course through years 10 and 11 including: their perspective on the differences between the syllabi; perspectives on the students' ability to cope with the change; and their perception on the impact the change has on student attitudes towards PDHPE.

The interviews were audio recorded and ranged from 10-15 minutes each and later transcribed verbatim. The interview data was thematically analysed (Merriam, 1998). Only themes identified by three or more students were further explored. The teacher interviews were coded based on the themes found in the student interviews. Student responses are identified in the following section as female $(\mathrm{F})$ and male $(\mathrm{M})$.

\section{Results}

Having arisen from an exploratory framework it is useful to present the data in a constant comparative way (Merriam, 1998) according to the six themes that were identified.

\subsection{The Student Experience of the Two Stages}

A number of trends in student experience of PDHPE were revealed by comparing the mean responses of questions using a Likert scale. Students were generally positive about their experience of year 10 and year 11 PDHPE. Figure 1 demonstrates a trend whereby males rated their enjoyment of year 10 PDHPE slightly higher than females. This tendency reversed in year 11 with females enjoying the subject more. The change was not statistically significant (one tailed Wilcoxon male $\mathrm{P}=0.37$, female $\mathrm{P}=0.66$ ). While student attitudes to year 11 were still positive, the reporting by both sexes that year 11 was 'harder' than year 10 was statistically significant in the one tailed Wilcoxon test ( $\mathrm{P}=0.000$ for males and $\mathrm{P}=0.002$ ). This means that year 11 is marginally more difficult for males than females. A gender difference was also apparent when analysing the change in the level of interest from year 10 to 11 . Females became slightly more motivated in year 11, but this was the opposite for males who found year 11 less motivating (see Figure 2.). The data was not statistically significant (one tailed Wilcoxon male $\mathrm{P}=0.59$, female $\mathrm{P}=0.18$ ). 


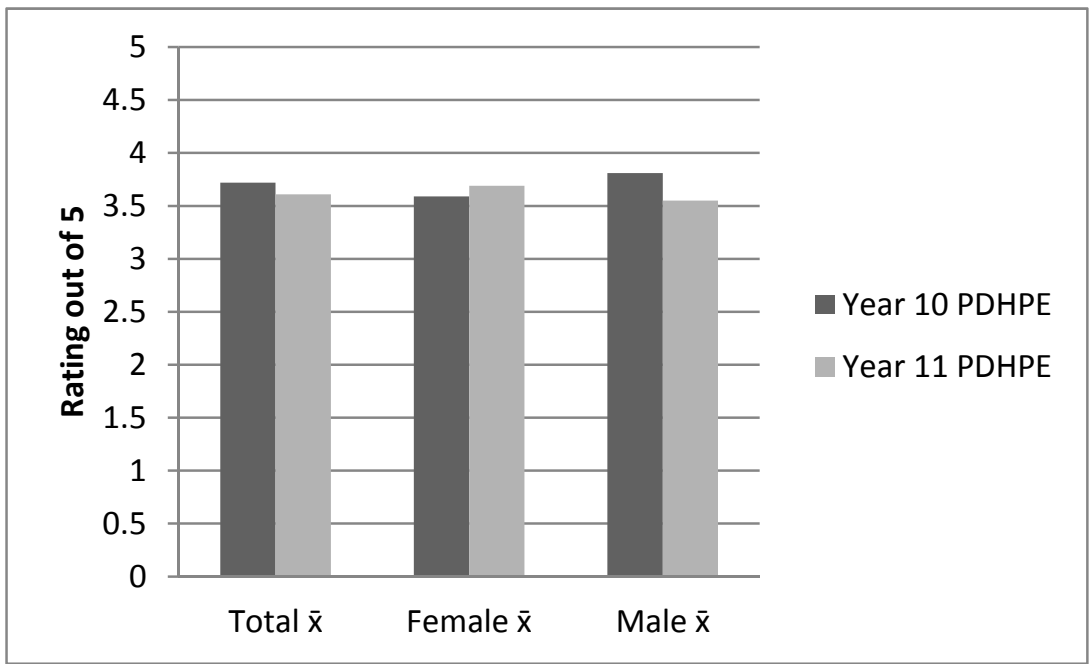

Figure 1. Perceived Positive Experience of Year 10 and 11 PDHPE

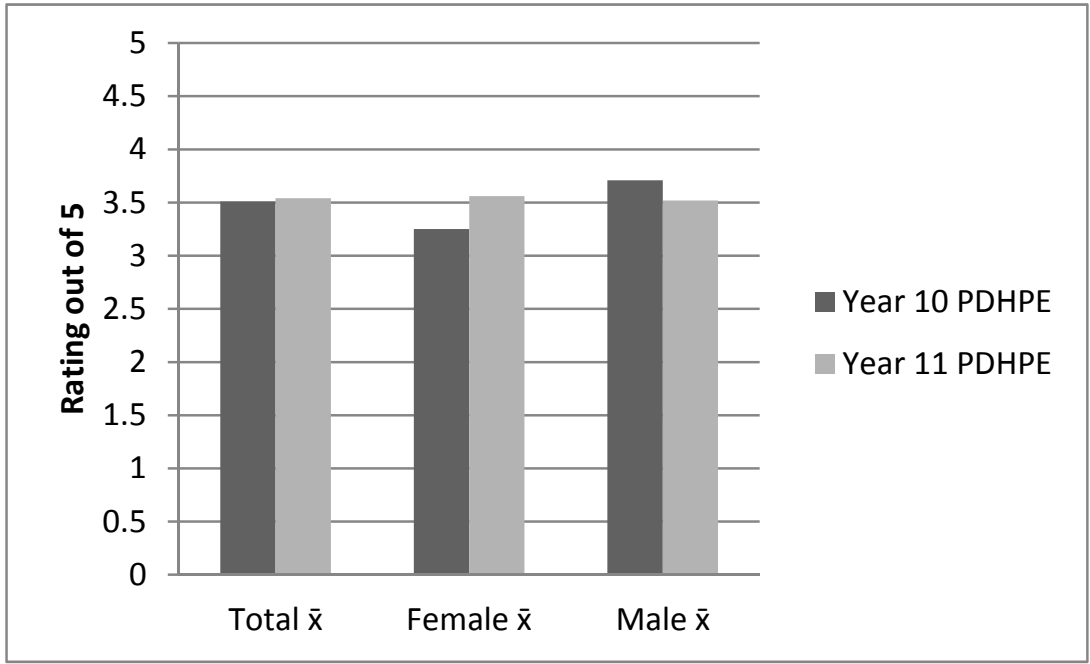

Figure 2. Perceived Interest of Year 10 and 11 PDHPE

Students reported that when they chose the subject in year 10 they had the expectation that the content would continue to spiral from that covered in the earlier years; that is, there would be a mix of theory and physical activity and that it "would be easy". However $35 \%(\mathrm{n}=13)$ reported their expectations were not met. These students reported that the amount of content was greater than expected and/or that they were disappointed with the lack of physical activity or "hands on lessons". Teacher 2 reflected on such student expectation:

the biggest change is that they think it's going to be like year 10, they can't get it out of their head that there is no practical component even though you tell them ... The students, 25 per cent of them think it is going to be the exact same, more laid back.

Four of the students interviewed supported this view noting that Year 11 was "too hard". All students interviewed indicated that the year 10 course was about "life skills" and "it was more common sense" (F1), whereas year 11 PDHPE was "about actual health and sport and exercises" (M5).

Students perceived that the change from year 10 to 11 was so dramatic that you "don't really need to have done year 10 PDHPE to do this [year 11 PDHPE]" (F1). When specifically asked whether the year 10 course prepared the students for year 11, F5 stated "no" and reasoned that it was "because they [the year 10 and 11 PDHPE course] are totally different subjects ... they both don't really overlap much". In a similar vein students discussed the higher order nature of the content. F5 talked about how in year 11 you were "meant to know more [in PDHPE], everything 
[became] more stressful for every subject, everything is in more depth". The higher order nature of this work was compounded by the increased weight that students gave to year 11. One student typified this shift to high stakes by stating:

[the] workload increased in year 11 and it's kind of like in year 10 you can get away with stuff ... but in year 11 if you miss one lesson you get put heaps far back from everyone else, you've got to concentrate all the time (M9).

The lack of preparation for the year 11 course, according to some students, contributed to the increased demands of the subject. In this way PDHPE was seen as unique as $49 \%$ of students indicated the change was more drastic than in English. Females felt this more so (63\%) than males (38\%). For some students the impact of the change was reduced by having studied Physical Activity and Sports Studies (PASS) in years 9 and 10. PASS is a stage 5 elective where students study "Foundations of Physical Activity", "Physical Activity and Sport in Society" and "Enhancing Participation in Sport" (NSWBOS, 2004, p. 12). These students were quick to point out, without prompting, that PASS was more similar to the year 11 than the year 10 PDHPE course.

\subsection{Attitudinal Response as a Result of the "big" Change - Signs of Confusion}

Four students appeared to exhibit signs of the attitudinal response of confusion or disengagement as a result of the change from years 10 to 11 PDHPE. Trends in the questionnaire data found that females were more likely to be bored and disengaged in year 10 than males. However, in year 11 this trend reversed with males being more likely to be bored and disengaged. The trends were not statistically significant (one tailed Wilcoxon male $\mathrm{P}=0.145$, female $\mathrm{P}=0.125$ ).

The change although an exciting prospect, became daunting for some students. When trying to summarise his feelings about this one student reported that when starting year 11 he was forced to "stand back a little bit, and go whoa" (M9). For some students the early confusion resulted in a negative impact on their grades and it was not until they received their exam results that they were spurred to change: 'well at first I sort of lagged behind ... that sort of affected my half yearlies, but I've made an effort since then' (F1).

Perhaps aware that the "big" change is difficult for some students, the teachers reported that they made attempts to mitigate the effects by assisting students to bridge the disconnect. Teachers achieved this through actively promoting PASS. Additionally, in an attempt to bridge the academic gap between year 10 and 11 the teachers provided supplementary academic skills lessons and marked draft assessment tasks reporting that they:

run before school classes for kids who are struggling with their work ... it's optional ... cause some kids think that PE is going to be light on content and they struggle a bit with the literacy component (Teacher 1).

\subsection{The Electives}

Analysis of the questionnaire revealed the electives studied in PDHPE have an impact on student attitudes. When asked about their favourite aspect of year 10 PDHPE, the most commonly ranked response amongst male and female students was 'physical activity' topics. In year 11 the topics of movement sciences were the most popular. The subject reported as the least favourite was health. There was a gender difference in attitudes whereby $62 \%$ of females reported that they enjoyed the health topics the least in comparison to $29 \%$ of males.

\subsection{What Students Want}

When questioned on the content students would like to see more of in year 11 PDHPE $80 \%$ of the students who completed the questionnaire suggested "more physical activity". A further comparison based on gender found males (48\%) were more likely than females (12.5\%) to want physical activity. Supporting these findings the students who were interviewed talked about their desire to see the inclusion of physical activity or a more practical approach in year 11. They communicated their strong passion to see physical activity included in the syllabus in examples such as the following:

I knew that we were not going to have any physical activity in year 11 from the year 10 information night, but", [in response to a pause with a facial gesture the interviewer asked: you still wanted it?] "yeah" (M5).

Another student offered a rather more complex understanding of the synergy between movement and health as a reason for her desire to have physical activity in year 11. She recognised however, the difficulty of assessing this strand at a high stakes level. The complexity warrants the inclusion of her extended response:

I think in year 11, I don't know if it's the same for guys, specifically for girls. I know that it's not in the syllabus, but I think, it is something that should be implemented in the preliminary course, because I think it 
is necessary and even though it can't necessarily be assessed on, for the kids that are choosing PDHPE that is what they are interested in ... just implementing a physical activity side of things that has to be done as well, would be what I would like to see (F2).

For one student, physical activity was seen as simply a need to escape the confines of the classroom: "I think it would help heaps of the boys in the class because they get all 'edgy' to run around and stuff" (M9). While for others, both male and female, they saw the possibility of extending some of the strands into more practically based activities:

well we do a lot of direct stuff in our class, I think if we put some physical activity into it, ... like biomechanics ... you could go outside and physically show us, or you could do activities to stimulate (sic) that better than just sitting in a classroom talking about it (M1).

\subsection{A Good Teacher}

Females $(17 \%)$ were more inclined to indicate that "time with friends" was a positive influence on their view of PDHPE; males in comparison identified the teacher (15\%). All of the students who were interviewed pointed out that they needed a "good teacher". This was characterised as someone that connected with them and made work relevant. F2 stated that she was "focused on teachers really creating a relationship in class, making kids feel comfortable, answering questions and stuff ". F1 also describes the need to connect with a teacher by saying that there needs to be room for "personal relationships with the teacher ... having sort of, one-on-one time".

Teachers appeared to share this view:

my style of teaching I think is very relational ... for a large percentage of them that works. So I like to think that if I'm noticing any student struggle I'm available for them for any questions or queries that they have (Teacher 2).

In contrast, the teacher was identified as a key external factor in influencing negative attitudinal change. This is indicated by a student who reported that year 11 has:

been a really good course ... I just think that if the teacher was, if I had a better teacher I think I'd be like really excited, but at the moment I'm just gliding through (M9).

M1 also isolated the teacher as a key factor disrupting his studies: "this year the teacher I have at the moment, I can't really communicate with as well. So I'm finding that a bit harder".

Interview data revealed that the change in teaching approaches from team teaching in year 10, which all students reported enjoying, to where only one teacher taught them in year 11 was seen as a negative by some students. This combined with a perception that one teacher had a different teaching approach resulted in a negative effect on attitude.

All students who talked about not responding well to their teacher were talking about a teacher of the opposite gender. The importance of this is that at this school students are split into classes in years 9 and 10 based on gender. A teacher reflected on the disadvantage a year 11 student may have because of this:

having not had me for a teacher from year 8, possibly year 7, then as a 16 year old [female] having a direct male teacher who you've never had before can ruffle a few feathers (Teacher 1).

\subsection{The Role of Power}

During most of the interviews there seemed to be an underlying feeling that students had a lack of power and minimal ability to affect their learning beyond the experience that was given to them. When contemplating whether students wanted to have a "voice" about how PDHPE was taught, the cohort was divided depending on their success with the subject.

The engaged students indicated that "if the individual has an issue with it [teachers approach] then you can't really help that problem" (F2) and "that doesn't really matter to me, I'm just a student, I just do what I'm told" (M5). However when prompted, disengaged students, or those students who felt that their learning was being inhibited, expressed a desire to affect change. F2 explained she would like the choice to change classes. Another student expressed his annoyance at not having the power to force change and indicated that this lack of voice is "frustrating" (M9).

An interesting contradiction was discovered in the data analysis where some students were concerned about not having the choice of elective subjects, while others indicated that they did. It unfolded that while one class was not afforded any choice as evidenced by: "I think it would be good if the class could decide together which one they do [PDHPE elective], because I think the teachers decide that for you" (F1), the other class did choose. In this case the 
students were informed of the teacher's strength before they made their choice "we have had the option, but, she said that I think I'm best at teaching first aid, and she said that you guys can choose and I'll teach you" (M1).

Although there appears to be some dilution of power around choice, it is clear for one of the teachers that he believes that he has the ultimate power to end a student's choice to study PDHPE:

some kids I strongly advise not to do our subject ... But then some kids who I've seen how they work in year 10, I'm out there selling my subject (Teacher 1).

This situation is seemingly brought about by the high stakes nature of the HSC for both students and teachers. The following clearly outlines how the pressures are shifted downwards:

when year 12 marks get back, you get a call from the principal for an interview ... [where I have to] explain my marks ... honestly, so I go I don't want him [bad student] in my subject because not only is it a bad mark but it is a waste of time (Teacher 1).

\section{Discussion}

Not surprisingly the students at this school reported that Year 10 is different to Year 11 PDHPE and that attitude change is evident. Students predominantly reported that they enjoyed senior PDHPE and for the most part get on with the business of study. This finding contrasts Fullan's (2007) research that found that $70 \%$ of students exhibited signs of an "alienation theme". This suggests that year 11 PDHPE at this school does not trigger alienation for most students and that the experience of change is more positive than that those at institutions studied by Fullan. Nevertheless, there were students who exhibited signs consistent with the dimension of alienation. These students wanted the power to effect change as they believed better results translated to greater likelihood of further employment. Key to this was ensuring that they had and access to a "good teacher" that connected with them.

This study found a variation in attitude with respect to gender. Females reported that they became more interested and less "bored" in year 11 than their male peers. Given a spike in attrition rates for males from years 11 to 12 in 1999 (NSWBOS, 2010) it may well be that the increasing academic demand is influencing this attitude. But there are other factors at play. At this school females are less likely to continue to year 12 . This rate is nearly twice as high as the state percentage in 2009, whereas their male peers are discontinuing at a rate four times less than the state percentage (NSWBOS).

Growing up and becoming more responsible and accountable for learning is a big change for these students. This change seems to be less problematic than the change in syllabus content however. Both students and teachers perceive a disconnect between years 10 and 11 . Given the years of conditioning of learning within a spiral curriculum, it is not surprising that students feel that a practical component should be included in year 11. This unexpected change is seen in the traits that are associated with confusion (Fullan \& Stiegelbauer, 1991) with students reporting the content as 'different' or unexpected. Linked to this is the reported failure by $35 \%$ of students to have their expectations met. Fullan (2006) argued that when expectations are not met, students can become confused or feel that they have been misled. The end result may well find students rejecting the subject completely (Hunter, 2009).

Students explained that they wanted some kinesthetic learning incorporated into year 11 to provide them with a break from the dense content and a chance to reenergise their efforts in class. Although the teachers appear to be aware of such desires they appeared to have limited empathy. Perhaps this is because, as Rudduck and Flutter (2000) explained, the student is at the bottom of the power hierarchy. Additionally due to the "high stakes" nature of senior study teachers too are focused on results. Indeed one teacher described the "massive pressure" associated with student performance and therefore a move away from direct instruction is unlikely (Burch \& Spillane, 2005). Nevertheless, some compromise might provide for a better transition and thus better engagement in the learning process (Fullan, 2006). Alternatively, the transition may be assisted by a more 'academic approach' to year 10 .

Consistent with the view that the study of PDHPE involves physical activity, students were more likely to enjoy the sport science topics over the health topics, regardless of gender. This corresponds with pre-service PDHPE teachers whose preference was human movement sciences over the sociocultural perceptive of health (Clarke, 2007). Notably the "health topics" in year 11 were the least "liked", more so by females than males. In fact, the students felt that the health core was a "bit dull". An investigation into why students do not appear to enjoy this subject, despite the importance placed on health as resource for everyday life, was beyond the scope of this research. Perhaps the construction of young people as 'the unhealthy "at risk" other' (Leahy \& Harrison, 2004, p. 133) turns young people away. Importantly these discourses of surveillance and regulation have been challenged and are to be replaced by a 
strengths based approach in the new K-10 syllabus (ACARA, 2012). Unfortunately it appears that the stage 6 syllabus will be unchanged and thus forecasts an ongoing subordination of the health curriculum. When given the opportunity to introduce a new elective, students showed no preference "as long as it involved physical activity". The choice was overwhelmingly selected by males. This is not surprising given Adair's (2009) claim that gender assumptions have been central to sport throughout white Australia's history, where males have been privileged and this attitude is still central to PE today (Connell, 2008).

Those students who identified as being disengaged reported that the teacher was a key factor in determining their attitude. This idea is reflected in the research of Hattie (2003) who identified the teacher as the single most powerful influence on achievement. However an unhelpful cycle appears to be at work at this school where, if according to a teacher a student was just "cruising along", it was appropriate for the teacher to conserve their energy and disengage from that student. As Hunter (2009, p. 91) has pointed out narratives around "young people as deficit, and marking clearly out what is the teacher's role is still strong". What follows is a stalemate where neither the student nor the teacher wants to develop a learning relationship. This is a far cry from Noddings' (2005) ethic of care. An analysis of the data revealed that these "disengaged" students had been previously taught in years 9 and 10 by a teacher of the same gender to themselves. Further research would be required to assess whether a causal relationship exists. However there are two explanations worth considering. The first is the amount of time a student has known a teacher and the subsequent rapport that may have resulted. Students told Buskist and Bryan (2001, para 15) that rapport 'increase[ed] their enjoyment of the teacher and subject matter'. The second has to do with gender. There is evidence that teachers can become conditioned to teaching their own gender, using language, ideas and understandings that are more engaging to the same gender (Gender Equity Taskforce for MCEECDYA, 1996, p. 9). Indeed, the Taskforce went so far as to note that " $[\mathrm{g}]$ endered ways of interacting with others and of understanding the world are ... deeply embedded into our language, our culture and our everyday practices"

Whatever the contributing factor, a continuous survey of perceptions and mandatory discussion between each student and the teacher could reverse negative perceptions of each other no matter the gender. Glasser (1998) argues students need to be involved in the dialogue around learning. If both parties are reminded and reassured of each other's commitment to learning, they may reengage in a quality learning environment that promotes a positive student/teacher relationship. Fortunately, the majority of students identified their teacher as being a positive influence. In this study students identified a "good" teacher as someone who developed a positive relationship with students and was there to help students when they wanted it. Essentially the students are identifying the fact that those teachers who provide "quality teaching" to promote student achievement are good teachers (Hattie, 2003).

\section{Conclusion}

The change in curriculum focus between years 10 and 11 in PDHPE does affect the attitudes of students. There are various external factors that influence these changes but happily the majority of students at this school were satisfied with their experience of PDHPE. Gender does not prevent an attitude shift but has an effect on the magnitude of the change. Nevertheless there is an underlying tension where students want to be moving and studying physical activity rather than being constrained to the classroom. There is also the hurdle of studying what appears to be a new subject in senior years.

One clear implication of this study is that schools should consider providing students with a regular "voice" on their own education. As it stands, students at this school seemed reserved and unfamiliar with having a voice on education. Nonetheless, when given an opportunity students provided valuable data that might improve learning and engagement. At this school students who perceive that their learning is inhibited do not want to be labeled as disengaged. These students still think about how their education could be improved and try to learn on their own rather than simply disengaging from the learning process. In order to reduce a cycle of disengagement based on potentially false perceptions, schools might open a dialogue with students where perceptions of each other are explored. Such a dialogue may improve attitudes and retention rates.

\section{Acknowledgements}

We would like to thank the students and teachers of the school who shared their thoughts and practices with us. Michelle Gorzanelli is also thanked for her thoughtful comments in preparing this manuscript. 


\section{References}

ACARA. (2012). Draft shape of the Australian curriculum: Health and Physical Education. Retrieved May 30,2013 from http://www.acara.edu.au/verve/_resources/Shape_of_the_Australian_Curriculum_Health_and_Physical_Educati on.pdf

Adair, D. (2009). Australian sport history: From the founding years to today. Sport in History, 29(3), 405-436.

Board of Studies New South Wales (2003). Personal Development Health and Physical Education 7-10 syllabus. Sydney: Board of Studies New South Wales.

Board of Studies New South Wales (2004). Physical Activity and Sports Studies Content Endorsed Course Years 7-10. Sydney: Board of Studies New South Wales.

Board of Studies New South Wales (2009). Personal Development Health and Physical Education 11-12 syllabus. Sydney: Board of Studies New South Wales.

Board of Studies New South Wales (2010). Retrieved March 15, 2010, from http://www.boardofstudies.nsw.edu.au

Brooker, R., \& Macdonald, D. (1999). Did we hear you? Issues of student voice in a curriculum innovation. Journal of Curriculum Studies, 31(1), 83-97.

Burch, P., \& Spillane, J.P. (2005). How subjects matter in district office practice: Instructionally relevant policy in urban school district redesign. Journal of Educational Change, 6, 51-76.

Buskist, W., \& Bryan, K. (2001). Rapport-Building: Creating positive emotional contexts for enhancing teaching and learning. APS $\quad$ Observer, $\quad$ Retrieved 3 April $15, \quad 2013$ fromhttp://www.psychologicalscience.org/index.php/publications/observer/2001/march-01/rapport-building-cre ating-positive-emotional-contexts-for-enhancing-teaching-and-learning.html

Cassidy, T., \& Ovens, A. (2009). Curriculum acoustics: Analysing the changing voice of the New Zealand health and physical education curriculum. In M. DinanThompson (Ed.), Health \& physical education: Issues for curriculum in Australia and New Zealand (pp.22-37). Melbourne: Oxford University Press.

Clarke, D. (2007). A Personal Development, Health and Physical Education (PDHPE) community of practice responding to curriculum change. Prepublished doctoral dissertation, University of Wollongong, Wollongong, NSW. Retrieved March 15, 2010 from http://ro.uow.edu.au/theses/42/

Cliff, K. (2007). A sociocultural perspective as a curriculum change in health and physical education. Prepublished doctoral dissertation, University of Wollongong, Wollongong, NSW. Retrieved March 15, 2010 from http://ro.uow.edu.au/theses/749/

Cliff, K. (2012). A sociocultural perspective as a curriculum change in health and physical education. Sport, Education and Society, 17(3), 293-311. http://dx.doi. org/ 10.1080/13573322.2011.608935

Connell, R.W. (2008). Masculinity construction and sports in boys' education: A framework for thinking about the issue. Sport. Education and Society, 13(2), 131-145. http://dx.doi/org/10.1080/13573320801957053

Cresswell, J.W., Plano Clark, V.L., Gutmann, M.L., \& Hanson, W.E. (2003). Advanced mixed methods research designs. In A.Tashakkori \& C. Teddlie (Eds.), Handbook of mixed methods in social and behavioural research (pp. 209- 240). Thousand Oaks: Sage.

Department of Education and Communities New South Wales (2011). Bloom's taxonomy of educational objectives and information skills. Retrieved November $\quad 3, \quad$ 2011, from http:/www.curriculumsupport.education.nsw.gov.au/policies/gats/assets/pdf/usci6kw01bloom.pdf

Fullan, M. (2006). Breakthrough. Thousand Oaks, CA: Corwin Press.

Fullan, M. (2007). The new meaning of educational change (4th ed.). New York: Teachers College Press.

Fullan, M., \& Stiegelbauer, S. M. (1991). The new meaning of educational change (2nd ed.). New York, NY: Teachers College Press.

Gender Equity Taskforce for the Ministerial Council on Education, Employment, Training and Youth Affairs. (1996). A Framework for Action on Gender Equity in Schooling. Part B - Perspectives on Gender Equity in Schooling. Retrieved April 1, 2013, from http://www.mceecdya.edu.au/verve/_resources/genderframwk23-73.pdf

Glasser, W. (1998). The quality school: Managing students without coercion (Rev. ed.). New York: HarperPerennial. 
Graham, G. (1995a). Physical education through students' eyes and in students' voices: introduction. Journal of Teaching in Physical Education, 14(4), 364 - 371.

Graham, G. (1995b). Physical education through students' eyes and in students' voices: implications for teachers and researchers. Journal of Teaching in Physical Education, 14(4), 478 - 482.

Halse, C., Honey, A., \& Boughtwood, D. (2007). The paradox of virtue: (re)thinking deviance, anorexia and schooling. Gender and Education, 19(2), 219-235.

Hattie, J. (2003). Teachers make a difference: What is the research evidence? Distinguishing expert teachers from novice and experienced teachers. Australian Council for Educational Research. October. Retrieved November 14, 2011, from https://www.det.nsw.edu.au/proflearn/docs/pdf/qt_hattie.pdf

Hunter, L. (2009). Should kids 'Be seen and not heard'?: Where are the students in HPE curriculum?. In M. DinanThompson (Ed.), Health \& physical education: Issues for curriculum in Australia and New Zealand (pp.80-105). Melbourne: Oxford University Press.

Kvale, S., \& Brinkmann, S. (2009). Interviews: Learning the craft of qualitative research interviewing $\left(2^{\text {nd }}\right.$ ed.). SAGE Publications.

Leahy, D., \& Harrison, L. (2004). Health and Physical Education and the production of the 'at risk self'. In J. Evans, B. Davies, \& J. Wright (Eds). Body knowledge and control studies in the sociology of Physical Education and Health (pp. 130-140). London: Routledge.

Lee, J., \& Macdonald, D. (2010). Are they just checking our obesity or what? The healthism discourse and rural young women. Sport, Education and Society, 15(2), 203-219. http://dx.doi.org/10.1080/13573321003683851.

Light, R., \& Kirk, D. (2000). High school rugby, the body and the reproduction of hegemonic masculinity. Sport, Education \& Society, 5(2), 163-176. http://dx.doi.org/10.1080/713696032

Merriam, S. (1998). Qualitative research and case study applications in education: Revised and expanded from case study research in education. San Francisco: Jossey-Bass.

Noddings, N. (2005). The challenge to care in schools (2nd ed.). New York, NY: Teachers College Press.

Onwuegbuzie, A., \& Collins, K. (2004). A framework for developing sampling designs in mixed methods research. Paper presented at the annual meeting of the Australian Association for Educational Research: Melbourne.

Rudduck, J., \& Flutter, J. (2000). Pupil participation and pupil perspective: Carving a new order of experience. Cambridge Journal of Education, 30(1), 75-89.

Rudduck, J., Chaplain, R., \& Wallace, G. (1996). School improvement: What can pupils tell us?. London: David Fulton.

StatistiXL. (2009). Statistical power for MS Excel. Retrieved November 3, 2011, from http://www.statistixl.com

Tashakkori, A., \& Teddlie, C. (2003). Handbook of mixed methods in social and behavioural research. Thousand Oaks: Sage. 